\title{
Prevalence of Nutrition Challenges in Pregnancy
}

\author{
Shadia Mohamed ${ }^{1}$, Asma Al Bagawi ${ }^{2}$ \\ ${ }^{1}$ University of Bahri \\ ${ }^{2}$ University of Hail/KSA
}

\begin{abstract}
Every pregnancy has its risks. Pregnancies are labeled "high risk" when there are complications with either the mother or the baby that need careful monitoring and observation. Objective: The purpose of this study to determined the nutrition challenges that facing pregnant women at Hail/KSA community. Concerning the lack of information available on Hail/KSA, the present study was designed to fulfill these purposes. Material and Method: 100 questionnaires was submitted to collected information about general characteristics of the study group, nutrition challenges, and dietary intake. Results: Most participants $41 \%$ educate to university level, $58 \%$ are work, $44 \%$ are obese. The common problems during pregnancy are heart burn 59\%, vomiting 52\% and anemia $32 \%$. There are significant relationship between stage of pregnancy and nutritional challenges, heartburn (p-value 0.048), Edema (p-value 0.026). Also the finding show significant relationship between nutritional challenges and nutrition supplementation.( $P$-value 0.00 for vomiting with vitamin).( P-value 0.001for heartburn with vitamin).( $p$-value 0.000 for morning sickness with vitamin and calcium). Conclusion: There are nutrition challenges facing women during pregnancy at Hail/KSA community. There are significant relation between these challenges and stage of pregnancy, nutrition supplementation and health problems before pregnancy.
\end{abstract}

Keywords: Nutrition challenges, pregnancy, women health, Birth risk, Nutrition Education

\section{Introduction}

Normal pregnancy occurs when healthy spermatozoa in adequate numbers penetrate receptive cervical mucus, ascend through a patent uterotubal tract, and fertilize a healthy ovam within 24 hours of ovulation. In the 6 or 7 days after ovulation, the implantation of the blastocyte occurs. On day 7 or 8 the trophoblast proliferates and invades the endometrium and begins to produce human chorionic gonadotropin (HCG). The major first trimester events involve organogenesis; and subtle insults during this time impact the development of the heart, brain, central nervous system, and kidneys.(1)

Maternal nutritional status has been evaluated primarily for infant birth weight, risk of neural tube defects (NTDs), and fetal alcohol syndrome. Birth weight is highly correlated with infant mortality and morbidity. Newborns born small for gestational age (SGA) are at increased risk for long-term health adversity such as hypertension, obesity glucose intolerance, and cardiovascular disease. Besides a woman's dietary intake, other factors such as air quality and purity of water can contribute adversely to a pregnancy. During prolonged periods of poor air quality (i.e., high levels of smog, particulates, and ozone), the rate of premature deliveries increases.(2)

\subsection{Complications of Pregnancy With Dietary Implications}

\subsubsection{Nausea and Vomiting}

Morning sickness or nausea and vomiting in pregnancy (NVP) affects $50 \%$ to $90 \%$ of all pregnant women during the first trimester of pregnancy, and it usually resolves around the 17 th week of gestation. There are no clear distinctions of when "morning sickness" becomes "hyper emesis gravid arum." usually women with "morning sickness" are functional and able to work and are not losing weight. This common form of morning sickness may be helped by simple dietary measures. Small, frequent, dry meals of easily digested carbohydrate-containing foods may be tolerated by some women' whereas protein foods may reduce nausea for others. (3). Although it has historically been suggested that liquids are best taken between meals, there has been no study to validate this recommendation In a small study of 14 nauseated women, it was shown that protein-dominated meals reduced nausea and arrhythmic activity to greater degrees than equi-caloric carbohydrate and fat meals and calorie-free meals; meal consistency did not affect symptom responses' but liquid meals decrease arrhythmias more than solids $\mathrm{d}$ id (3).

More research is needed. Although some women often do not tolerate fats because of the olfactory aspect of hot foods, room temperature foods containing fat such as potato chips and snack foods may be preferred by a sick woman. Unfortunately there is no cure-all. It is suggested that the woman suffering with nausea eat whatever reduces the sensation of ,nausea. and avoid odors that trigger nausea. Other elements that can increase nausea include motion, noise( including gum snapping and "boom boxes"), bright lights, and adverse climate conditions. When early pregnancy is characterized by excessive vomiting and weight loss, the client likely has hyperemesis grayidarum, and her nutritional status is greatly compromised. (4)

Fluid and electrolyte imbalances can require hospitalization for rehydration and nutritional support. Historically hyperemesis was considered by some to be psychiatric in nature because women became apathetic regarding their pregnancies and often requested care by their own mothers. Cognitive alterations accompany starvation, and physical brain changes can be found on a magnetic resonance image (MRI). In addition, consider that some of the medically administered therapies have included injections of husband's blood and application of leeches (5).

One of the most common complications of hyperemesis gravidarum is Wernicke's encephalopathy. Wernicke's has commonly been associated with alcoholism but has many other etiologies, mainly starvation. Other physical

\section{Volume 4 Issue 12, December 2015}




\section{International Journal of Science and Research (IJSR) \\ ISSN (Online): 2319-7064 \\ Index Copernicus Value (2013): 6.14 | Impact Factor (2014): 5.611}

deleterious outcomes noted in the medical literature include ruptured esophagus, acute renal failure, visualdeterioration, and splenic avulsion. (6).

The nutritionist needs to be vigilant to avoid the real problem of "refeeding syndrome" in starved women and follow electrolytes such as phosphorous, magnesium, and potassium closely and replenish in a timely fashion. Low levels of electrolytes can result in cardiac irregularities and respiratory failure. Hyperemesis gravidarum develops in about $2 \%$ of pregnancies (7) and is associated with an increase in maternal free thyroid hormone as well as several other hormones, including a variant of the HCG molecule (8).

Hospitalization is usually indicated when dehydration occurs Tube feeding may be used and should be considered before parenteral nutrition because of relatively fewer complications. Enteral nutrition does not guarantee an end to nausea, vomiting, and retching in all cases (9).

Nasogastric feedings, percutaneous endoscopic gastrosromy (PEG), jejunostomy feedings and PEG with a jejunal port (10) have been tried. It is not common to give pregnant women anti-anxiety medications during tube insertion because of the potential of fetal risk, and it is important to respect the wishes of the client if she declines enteral nutrition. The provider needs to be sensitive to the reality that many ill women may choose pregnancy termination out of 'desperation as a means to eliminate nausea and vomiting (11). Parenteral nutritional support may also be used in. One nuisance factor is excess saliva. Salivary output can be substantial and can be a source of lost. (12).

\subsubsection{Heart burn}

Gastric esophageal reflux is a common occurrence during the latter part of pregnancy, and it often occurs at night. In most cases this is an effect of pressure of the enlarged uterus on the intestines and stomach, which, in combination with the relaxation of the esophageal sphincter, may result in regurgitation of stomach contents into the esophagus. Relief may occur by suggesting that the pregnant woman eat frequent small meals. Dinner plates can be changed for luncheon plates to remind a woman and her family about reduced gastric volume

\subsubsection{Constipation and Hemorrhoids}

Pregnant women will become constipated if they fail to consume adequate water and fiber. And it is not uncommon for women in the first trimester who are being treated with Zofran (ondansetron) for nausea and vomiting to become extremely constipated. Straining during stooling-called valsalva increases the risk for hemorrhoids. Increased consumption of fluids, fiber-rich foods and dried fruits (especially prunes and figs) usually controls these problems, but some women may also require a bulking type of stool softener. (13)

\subsubsection{Edema and Leg Cramps}

Mild, physiologic edema is usually present in the extremities in the third trimester and should not be confused with the pathologic, generalized edema associated with pregnancy induced hypertension. Normal edema in the lower extremitiesbin pregnancy is caused by the pressure of the enlarging uterus on the vena cava, obstructing the return of blood flow to the heart. When a woman reclines on her side, the mechanical effect is removed, and extra-vascular fluid is mobilized and eventually eliminated by increased urine output. No dietary intervention is required. Calcium supplementation for leg cramps during pregnancy has been used extensively, although only three studies met the criteria for analysis by the Cochrane Review, and the use of calcium for leg cramps in pregnancy is not supported (14). The authors suggest that the best evidence for the relief of leg cramps is use of magnesium lactate or citrate. Magnesium supplementation may relieve leg cramps because pregnancy and lactation can lead to a secondary magnesium deficiency as evidenced by low serum magnesium levels. Signs of magnesium deficiency include muscle tremor ataxia, tetany, constipation, and cramps; thus supplemental magnesium may relieve the leg cramps associated with pregnancy or lactation.(14)

\subsubsection{Diabetes Mellitus}

Individualized, expert care is needed for the nutritional management of the pregnant woman with diabetes. Based on a nutritional history and assessment early in pregnancy, or preferably preconception, the woman's meal plan in the form of lowered carbohydrates should be adapted for pregnancy by a skilled nutritionist as part of the health care team. The risk of PIH, macrosomia, chorioamnionitis, prematurity, intrauterine fetal demise (IUFD), and fetal morbidity is significantly greater in the pregnant women with diabetes than in the pregnant women without diabetes. Recent evidence suggests that women who do not meet the criteria to be classified as diabetic but have elevated blood glucose during pregnancy also carry significant risk for pregnancy complications, including macrosomia, prematurity, and chorioamnionitis (15).

These adverse outcomes can be avoided with specialized care, including ongoing involvement with the nutritionist, and the risk of complications can be reduced to the same level as seen in pregnant women who do not have diabetes. Successful pregnancy requires adequate dietary intake to meet the growth needs of the fetus, prevent ketosis, and prevent depletion of maternal nutritional stores. Maintenance of optimal blood glucose levels with avoidance of ketosis is an important goal of therapy. Gestational diabetes is usually diagnosed after 24 weeks' gestation and may affect as many as $5 \%$ to $10 \%$ of all pregnant woman. Although symptoms are similar to those of diabetes mellitus, including glycosuria and elevated blood glucose, there is also a greater likelihood of developing preeclampsia. Infants whose mothers have gestational diabetes are at increased risk for perinatal mortality, as well as for prematurity with its attendant complications.

If the mother's Blood glucose is not well controlled, the infant is at risk for macrosomia, or infant birth weight greater than the $90^{\text {th }}$ percentile or $4000 \mathrm{~g}$. Stillborn babies at term are tragic but, not common. In addition, women who have experienced gestational diabetes are at future risk for type 2 diabetes mellitus within 15 years of the index pregnancy. Gestational diabetes is treated largely through dietary changes (some calorie restriction may be necessary)

\section{Volume 4 Issue 12, December 2015}




\section{International Journal of Science and Research (IJSR) \\ ISSN (Online): 2319-7064}

Index Copernicus Value (2013): 6.14 | Impact Factor (2014): 5.611

and moderate exercise to maintain appropriate weight gain Insulin is used if glucose levels do not respond to dietary manipulations. Dietary manipulation includes limiting carbohydrates at breakfast 10 to 30 grams with the addition of 2 to 3 ounces of protein mid morning to decrease hunger and increase compliance. The daily caloric needs of the client need to be configured in the dietary plan. Just counting carbohydrates is only one third of the dietary prescription; contributions from protein and fat need consideration. Blood glucose levels are often monitored four to six times a day with a goal of less than $90 \mathrm{~g} / \mathrm{dl}$ for fasting and less than 120 $\mathrm{mg} / \mathrm{dl}$ after meals. The oral hypoglycemic agents such as metformin are being used in some centers. (15)

\subsubsection{Pregnancy-induced Hypertension}

Pregnancy-induced hypertension ( $\mathrm{PIH}$ ) includes gestational hypertension and preeclampsia/eclampsia Gestational hypertension is a maternal blood pressure equal to or greater than 140/90 with no protein urea that develops after mid pregnancy. These women may develop preeclampsia' which is defined b y a systolic blood pressure of 140/90 or more or a diastolic blood pressure of $90 \mathrm{~mm} \mathrm{Hg}$ or more and urinary protein of $300 \mathrm{mg}$ or more in a 24-hr urine sample. Severe preeclampsia is defined as a systolic blood pressure of 160 or more or a diastolic blood pressure of $110 \mathrm{~mm} \mathrm{Hg}$ or more and $5 \mathrm{~g}$ of protein in a 24-hr urine sample. Preeclampsia is associated with decreased uterine blood flow, owing to vasospasm leading to reduced placental size, compromised fetal nourishment, and an IUGR fetus. Measurement of umbilical blood flow is also helpful. "Absent end diastolic flow" signifies adversity to the fetus as blood flow through the umbilical cord is encountering significant resistance from the placenta. "Reversed end diastolic flow" is a more ominous finding, meaning that blood flow to the fetus is meeting such vascular resistance that it is moving in the opposite direction. In addition, preeclampsia may result in maternal end-organ damage such as liver impairment, renal impairment, cerebral vascular events, and retinal damage. Vasospasm, intravascular volume depletion, and subsequent Hemoconcentration are also present with severe PIH. The condition usually develops in the third trimester affectingabout $5 \%$ to $8 \%$ of the obstetric population, particularly women who are nulliparous, older than 40 years, obese, and black and who have a family history of PIH. Other risk factors include chronic hypertension, chronic renal disease, diabetes mellitus, a twin gestation, and homozygosity or heterozygosity for angiotensinogen gene T235. Insulin resistance syndrome has also been suggested as a cause for PIH (16).

The incidence of preeclampsia is known to be increased in women with some autoimmune diseases such as type I diabetes and rheumatoid arthritis. There is a reduction in the levels of circulating 1,25 $(\mathrm{OH}) 2 \mathrm{D} 3$ in preeclamptic patients compared with normotensive or chronically hypertensitive controls, which may be caused by a disturbance in 1 ahydroxylation within the placenta/deciduas.. (17)

\subsubsection{Eclampsia}

is PIH resulting in grand mal seizures. Symptoms of PIH that increase the concern for seizure are dizziness, headache, visual disturbances, facial edema, anorexia, nausea, and vomiting. Fetal death often results in women who develop eclampsia. A small percent of cases of eclampsia present in the postpartum period. Eclampsia can be fatal to the mother if not treated promptly. Magnesium Supplementation. Magnesium supplementation has also been recommended to prevent and treat preeclampsia and eclampsia with some effectiveness. Previous attempts to treat preeclampsia have included severe sodium restriction and diuretics. Sodium restriction and diuretics do not reduce blood pressure, limit weight gain, or reduce the amount of protein urea in this condition; and they have no place in the treatment or prevention of preeclampsia. The use of diuretics in women with PIH would lead to fluid loss and a decrease in intravascular volume; thus further compromising the fetus. Restricted energy intake also has no role in the prevention of PIH.(18) (19)

\subsubsection{Vaginal infections}

Infections play a major role in premature contractions and subsequent early deliveries. Bacterial vaginosis (BV is one such infection, affecting many pregnant women. The use of probiotics in pregnancy women with $\mathrm{BV}$ is compelling since certain lactobacilli strains can safely colonize the vagina and displace and kill such pathogens as Gardnerella vaginalis and Escherichia coli (20)

\section{Results and Discussion}

Table 1: General characteristics of the population

\begin{tabular}{|c|c|c|c|}
\hline Variables & Characteristics & Frequency & Percentage \\
\hline \multirow{4}{*}{ Education } & Primary & 6 & 6 \\
\hline & Secondary & 28 & 28 \\
\hline & University & 41 & 41 \\
\hline & Higher & 25 & 25 \\
\hline \multirow{2}{*}{ Occupation } & Work & 58 & 58 \\
\hline & Not work & 42 & 42 \\
\hline \multirow{3}{*}{$\begin{array}{l}\text { Economic } \\
\text { status }\end{array}$} & Low & 6 & 6 \\
\hline & Medium & 22 & 22 \\
\hline & High & 72 & 72 \\
\hline \multirow{3}{*}{$\begin{array}{c}\text { Stage of } \\
\text { pregnancy }\end{array}$} & Less than 3 months & 18 & 18 \\
\hline & $3-6$ months & 11 & 11 \\
\hline & More than 6 month & 71 & 71 \\
\hline \multirow{8}{*}{ Problems } & Morning sickness & 75 & 75 \\
\hline & Vomiting & 59 & 59 \\
\hline & Heart burn & 52 & 52 \\
\hline & Constipation & 18 & 18 \\
\hline & Edema & 18 & 18 \\
\hline & Anemia & 32 & 32 \\
\hline & Diabetes & 10 & 10 \\
\hline & Hypertension & 5 & 5 \\
\hline \multirow{4}{*}{ BMI } & Underweight & 1 & 1 \\
\hline & Normal & 23 & 23 \\
\hline & Overweight & 44 & 44 \\
\hline & Obese & 40 & 40 \\
\hline
\end{tabular}

Table 1. Represents the general characteristics of the study group. $41 \%$ study till university level, 58\% work, $72 \%$ have high economic status, $71 \%$ at more than 6 month stage of pregnancy. The common nutritional problem include: morning sickness $75 \%$, heartburn $52 \%$, vomiting $59 \%$ and $32 \%$ of the respondents are anemic.

\section{Volume 4 Issue 12, December 2015}




\section{International Journal of Science and Research (IJSR) \\ ISSN (Online): 2319-7064}

Index Copernicus Value (2013): 6.14 | Impact Factor (2014): 5.611

Table 2: Intake of different food groups

\begin{tabular}{|c|c|c|c|}
\hline Food groups & Category & Frequency & Percentage \\
\hline \multirow{3}{*}{ Eggs + meat } & No intake & 6 & 6 \\
\hline & Intake/day & 49 & 49 \\
\hline & Intake/week & 34 & 34 \\
\hline \multirow{3}{*}{ Milk } & No intake & 9 & 9 \\
\hline & Intake/day & 67 & 67 \\
\hline & Intake/week & 20 & 20 \\
\hline \multirow{3}{*}{ Fish } & No intake & 23 & 23 \\
\hline & Intake/day & 5 & 5 \\
\hline & Intake/week & 36 & 36 \\
\hline \multirow{3}{*}{ Beans/lentils } & No intake & 38 & 38 \\
\hline & Intake/day & 12 & 12 \\
\hline & Intake/week & 24 & 24 \\
\hline \multirow{3}{*}{ Chocolate } & No intake & 21 & 21 \\
\hline & Intake/day & 46 & 46 \\
\hline & Intake/week & 22 & 22 \\
\hline \multirow{3}{*}{ Chips } & No intake & 23 & 23 \\
\hline & Intake/day & 24 & 24 \\
\hline & Intake/week & 29 & 29 \\
\hline \multirow{3}{*}{$\begin{array}{l}\text { Green leafy } \\
\text { vegetables }\end{array}$} & No intake & 4 & 4 \\
\hline & Intake/day & 52 & 52 \\
\hline & Intake/week & 34 & 34 \\
\hline \multirow{3}{*}{ Fruits } & No intake & 15 & 15 \\
\hline & Intake/day & 34 & 34 \\
\hline & Intake/week & 37 & 37 \\
\hline \multirow{3}{*}{ Juices } & No intake & 5 & 5 \\
\hline & Intake/day & 71 & 71 \\
\hline & Intake/week & 15 & 15 \\
\hline
\end{tabular}

Table2. Represent the Intake of different food groups. 49\% of the respondent intake meat and egg weekly, 67\% intake milk daily, Only 36\% intake fish weekly, 46\% intake chocolate daily, $52 \%$ intake green vegetable daily, $71 \%$ intake juices daily. Poor intake of protein food and high intake of calorie food.

Table 3: Correlation of nutritional challenges with the stage of pregnancy

\begin{tabular}{|c|c|c|c|c|c|}
\hline \multirow{2}{*}{$\begin{array}{c}\text { Nutritional } \\
\text { challenges }\end{array}$} & & \multicolumn{3}{|c|}{ Stage of pregnancy } & \multirow{2}{*}{ P value } \\
\cline { 3 - 6 } & & $\begin{array}{c}\text { Less } \\
\text { than } 3 \mathrm{~m}\end{array}$ & $3-6 \mathrm{~m}$ & $\begin{array}{c}\text { More } \\
\text { than } 6 \mathrm{~m}\end{array}$ & \\
\hline Constipation & Yes & 4 & 6 & 13 & \multirow{2}{*}{$0.027^{* *}$} \\
\cline { 2 - 6 } & No & 58 & 9 & 14 & \\
\hline \multirow{2}{*}{ Heartburn } & Yes & 6 & 8 & 38 & \multirow{2}{*}{$0.048^{*}$} \\
\cline { 2 - 5 } & No & 12 & 2 & 33 & \\
\hline Vomiting & Yes & 10 & 7 & 41 & \multirow{2}{*}{0.73} \\
\cline { 2 - 5 } & No & 8 & 3 & 30 & \\
\hline \multirow{2}{*}{ Edema } & Yes & 3 & 1 & 14 & \multirow{2}{*}{$0.026^{* *}$} \\
\cline { 2 - 5 } & No & 57 & 15 & 9 & \\
\hline \multirow{2}{*}{ Hypertensive } & Yes & 1 & 1 & 3 & \multirow{2}{*}{0.733} \\
\cline { 2 - 5 } & No & 17 & 9 & 68 & \\
\hline
\end{tabular}

Significant*

Table No.3. Represents the nutritional challenges and stage of pregnancy. There is significant relationship between Constipation ( P-value 0,027), Heartburn (P-value 0,048), Edema (p-value 0,026) with stage of pregnancy. There is no relation between vomiting and stage of pregnancy.

Table 4: Correlation of nutritional challenges with nutrient supplementation

\begin{tabular}{|c|c|c|c|c|}
\hline $\begin{array}{c}\text { Nutritional } \\
\text { challenges }\end{array}$ & Vitamin & Calcium & Iron & Folic acid \\
\hline Morning sickness & $0.000^{* * *}$ & $0.000^{* * *}$ & $0.001^{* *}$ & $0.006^{* *}$ \\
\hline Vomiting & $0.000^{* * *}$ & 0.072 & 0.332 & 0.659 \\
\hline Heart burn & $0.001^{* *}$ & 0.488 & 1.000 & 0.761 \\
\hline Constipation & 0.188 & $0.000^{* * *}$ & $0.000^{* * *}$ & $0.000^{* * *}$ \\
\hline Edema & 0.175 & $0.000^{* * *}$ & $0.000^{* * *}$ & $0.000^{* * *}$ \\
\hline Anemia & 0.324 & 0.088 & $0.021^{*}$ & $0.006^{* *}$ \\
\hline Diabetes & $0.005^{* *}$ & $0.000^{* * *}$ & $0.000^{* * *}$ & $0.000^{* * *}$ \\
\hline Hypertensive & $0.000^{* * *}$ & $0.000^{* * *}$ & $0.000^{* * *}$ & $0.000^{* * *}$ \\
\hline
\end{tabular}

\section{Significant*}

Table 4. Shows significant relationship between nutritional challenges and nutrition supplementation. ( P-value 0.00 for morning sickness, vomiting, and hypertension with vitamins supplementation),( P-value 0.001 for heartburn with vitamin supplementation $\mathrm{s}$ ( $\mathrm{p}$-value 0.005 for Diabetes with vitamin supplementations. There is relation between morning sickness, constipation, Edema, Diabetes, and hypertension with calcium intake during pregnancy.pvalue 0.000 . Iron, folic acid intake have a relation with constipation, Edema, Diabetes and hypertension(pvalue 0.000

Table 5: Correlation of nutritional challenges with Health problems before pregnancy

\begin{tabular}{|c|c|c|c|c|c|c|c|}
\hline \multirow{2}{*}{$\begin{array}{l}\text { Nutritional } \\
\text { challenges in } \\
\text { pregnancy }\end{array}$} & \multicolumn{6}{|c|}{ Complications before pregnancy } & \multirow{2}{*}{$P$ value } \\
\hline & & Anemia & HTN & Colic/chest pain & Diabetes & No complains & \\
\hline \multirow{2}{*}{ Anemia } & Yes & 8 & 0 & 1 & 0 & 25 & \multirow{2}{*}{$0.010^{* *}$} \\
\hline & No & 0 & 3 & 1 & 4 & 54 & \\
\hline \multirow{2}{*}{ Diabetes } & Yes & 1 & 3 & 1 & 4 & 5 & \multirow{2}{*}{$0.004 * *$} \\
\hline & No & 7 & 0 & 1 & 0 & 74 & \\
\hline \multirow{2}{*}{ HTN } & Yes & 1 & 1 & 0 & 0 & 3 & \multirow{2}{*}{0.327} \\
\hline & No & 7 & 2 & 2 & 4 & 76 & \\
\hline
\end{tabular}




\section{International Journal of Science and Research (IJSR) \\ ISSN (Online): 2319-7064 \\ Index Copernicus Value (2013): 6.14 | Impact Factor (2014): 5.611}

Table 5. Shows relationship between nutritional challenges and health problems before pregnancy. There is significant relation between anemia as nutrition challenge and Anemia before pregnancy, HTN, chest pain, and Diabetes ( P-value 0.010). Also there is significant relation between Diabetes as nutrition challenge and Anemia before pregnancy, HTN, chest pain, and Diabetes ( $\mathrm{P}$-value 0.004). This indicate that if the women have health problem before pregnancy, she can face nutritional challenges during pregnancy which affect also the outcome of the pregnancy.

\section{Conclusion}

There are nutrition challenges facing women at Hail community. There are significant relation between these challenges and stage of pregnancy, nutrition supplementation and health problems before pregnancy. There are no significant relation between dietary intake and challenges facing pregnant women.

\section{Recommendation}

1) Nutrition education programs should be conducted at Hail/KSA community to highlight the risk of challenges during pregnancy for health and safety of mothers and their outcome.

2) Further investigation about causes and how to overcome nutrition challenges between women at Hail community.

\section{References}

[1] Kathleen Mahan, L; (2008): Kruse's Food and Nutrition Therapy. Nutrition During Pregnancy \& Lactation. International Edition, 12e ISBN: 978-0-8089-2378

[2] Mennes $\mathrm{T}$ et al: Impact of ambient air pollution on birth weight in Sydney Australia Occup. Environ Med 62: $52+, 2005$. Miles HL et al: Fetal origins of adult disease as: pediatric Perspective R, $n$ Endocrinal Metabol. Dis. 6 : 261,2005.

[3] Jednak MA et al: Protein meals reduce nausea and gastric wave dysrhythmic activity in first trimester pregnancy,-Am J Physiol.277 (4 pt 1 ):G855, 1999.

[4] Erick M: Managing morning sickness :a survival guide for pregnant women Boulder, Colo, 2004, Bull Publishing.

[5] Munch S: Chicken or the egg? The biologicalpsychological controversy surrounding hyperemesis gravidarum, Soc. Sci. Med' 55 :126,7 2002.

[6] Henry RJW, Vadas RA: Spontaneous mature of the esophagus following severe vomiting in early pregnancy: a case report, Br J Obstet. Gynecol. 93:392, 1986.

[7] Erick M: Hyperolfaction and hyperemesis gravidarum: What is the relationship? Nutr. Rea 53:289, 1995.

[8] Panesar NS et al: Are thyroid hormones or h CG responsible for hyperemesis gravidarum? A matched paired study in pregnant Chinese women, Acta. Obstet Gynecol Scand 80:519' 2001.

[9] Erick, M. Enteral nutrition and hyperemesis gravidarum: another perspective Women's Health and Reproductive Nutrition Practice Group newsletter, Chicago, Fall 2006, American Dietetic Association.
[10] Irving PM et al: Percuraneous endoscopic gastromy with a jejunal port for severe hyperemesis gravidarum, Eur. J. Gastro. enternal . Hepatol 16:937, 2004.

[11] Mazzotta P et al: Factors associated with elective termination of pregnancy among Canadian and American women with nausea and vomiting of pregnancy, / Psychosom. Obstet Gynaecol 22:7, 2001.

[12] BaileyL B, Berry RJ: Folic acid supplementation and the Occurrence of congenital heart defects ,or of acidic lefts ,multiple births, and miscarriage Am J Clin. Nutr. 81:1235,2005

[13] Erick M: Epigenetics: curing edge science in Maternal and fetal nutrition. Update of vitamin D, calcium, iron, iodine and omega 3 fatty acids. Presented at the Food, Nutrition, Conference and Exhibition of the American Dietetic Association, St Louis, Mo, October 25, 2005.

[14] Young GL, Jewell D: Interventions for leg cramps in pregnancy, Cochran Database Sys Rteu C D 000121, 2 000 .

[15] Scholl TO et al: Maternal glucose concentration influences fetal growth, gestation , and pregnancy complications A, m J Epidemol. 154:514,2 001.

[16] Solomon. C G, Seely. E W: Brief review: hypertension in pregnancy: a manifestation of the insulin resistance syndrome? Hypertensio3n7: 232, 2001.

[17] Chappell L C et a1: Vitamin C and E supplementation in women at risk of preeclampsia is associated with changes in indices of oxidative stress and placental function, Am J Obstet. Cinecol 187:7 77, 2002.

[18] Rumbold. AR et al: Vitamins $\mathrm{C}$ and $\mathrm{E}$ and risks of preeclampsia and perinatel complications $\mathrm{N}$, Eng $\mathrm{J}$ Med J54:1796,2006.

[19] Poston L et al: Vitamin C and vitamin $\mathrm{E}$ in pregnant women at risk for preeclampsia (VIP trial): randomized placebo controlled trial, Lancet $367: 1145$, 2006'

[20]Reid G, Bocking A: The potential for probiotics to prevent bacterial $\mathrm{v}$ diagnosis and preterm labor, A $\mathrm{m} \mathrm{J}$ Obstet. Gynecol. 189: 1202,2003

\section{Author Profile}

Shadia Mohamed Idris received the B.Sc., M.Sc. \& PhD degrees in Family Science from Ahfad \& Khartoum University in 1998, 1997 and 2000, respectively. During 1998-2014, she works at Ministry of health , University of Juba , university of Bahri and University of Hail / KSA. She worked now, as Associate professor at University of Bahri-Sudan.

Asmaa Al bagawi , B.Sc. at University of Hail/KSA. 